\title{
Predictors of Urinary Tract Infections in Children and Antibiotic Susceptibility Pattern in the Buea Health District, South West Region, Cameroon
}

\author{
Che Pantalius Nji $\mathbb{D}^{1}{ }^{1}$ Jules Clément Nguedia Assob, ${ }^{2}$ \\ and Jane-Francis Tatah Kihla Akoachere $\mathbb{D}^{1}$ \\ ${ }^{1}$ Department of Microbiology and Parasitology, Faculty of Science, University of Buea, P.O. Box 63, Buea, \\ South West Region, Cameroon \\ ${ }^{2}$ Department of Biomedical Sciences, Faculty of Health Sciences, University of Buea, P. O. Box, 63 Buea, \\ South West Region, Cameroon \\ Correspondence should be addressed to Jane-Francis Tatah Kihla Akoachere; jakoachere@yahoo.com
}

Received 27 March 2020; Revised 3 October 2020; Accepted 16 October 2020; Published 31 October 2020

Academic Editor: Shin-ichi Yokota

Copyright (c) 2020 Che Pantalius Nji et al. This is an open access article distributed under the Creative Commons Attribution License, which permits unrestricted use, distribution, and reproduction in any medium, provided the original work is properly cited.

\begin{abstract}
Urinary tract infections (UTI) are among the most common pediatric infections and if not promptly diagnosed and treated, it could cause long term complications. Worldwide and in Cameroon, little attention has been paid to this growing problem in the pediatric population. Identification of risk factors will contribute significantly to prevention. A cross-sectional case-control study was carried out in children $\leq 15$ years to identify the risk factors of UTI, etiologic agents, and their antibiotic susceptibility. Samples (urine) were collected from in and outpatients with symptoms of UTI attending two health facilities in Buea. Controls were age- and sex-matched children in the community and those visiting these health facilities for unrelated reasons. Samples were analyzed by microscopy, culture, and antibiotic susceptibility of bacteria isolates tested by the disc diffusion technique. Questionnaires were administered to collect sociodemographic, clinical characteristics and data on risk factors. Odds ratios and bivariate and multivariate analyses were used to assess the relationship between predictors (symptoms and risk factors) and UTI. $P<0.05$ was considered significant. A total of 405 participants (200 cases and 205 controls) were investigated. UTI prevalence was $12 \%$ in cases. From the UTI cases, bacteria was the major cause of infection, with E. coli (39.4\%) predominating. Parasitic organisms, Trichomonas vaginalis $(0.5 \%)$ and Schistosoma spp $(0.5 \%)$, and yeast $(6 \%)$ were also detected. Urinary urgency $(F=4.98, P=$ $0.027)$ and back pain $(F=12.37, P=0.001)$ were associated to UTI following bivariate analysis. These parameters could be used to predict UTI in the pediatric population in the study area. Third generation cephalosporins: ceftriaxone (90.1\%) and cefadroxil (85.4\%) were the most effective and thus recommended for treatment.
\end{abstract}

\section{Introduction}

Urinary tract infections (UTIs) are among the most commonly encountered infections in the pediatric age group in both the community and hospital setting, representing $1.8 \%$ of all pediatric hospitalizations [1]. The incidence of emergency department visits for pediatric UTI is on the rise resulting in an alarming increase in emergency department expenses [2]. UTI constitutes a significant economic burden and healthcare utilization. Studies predict that about 8-10\% of girls and 2-3\% of boys will have symptomatic UTI before the age of 7, with frequency higher in males in their first three months of life and with increasing age, the frequency becomes higher in females than males [3]. In children, the prevalence of community-acquired urinary tract infection has been seen to vary with season [4].

Causative agents of UTI in the pediatric population are similar to those of the rest of the population. Microorganisms 
of the bacterial origin are the main cause of UTI, although viruses are increasingly recognized as a cause of lower UTI among immunocompromised individuals [5]. UTIs of the fungal origin are mostly caused by Candida albicans [6]. Parasitic diseases such as schistosomiasis and trichomoniasis give rise to renal and lower urinary tract diseases [7]. Most UTIs in children are monomicrobic, with E. coli being the most frequently isolated pathogen $[8,9]$. Other members of the Enterobacteriaceae as well as Pseudomonas aeruginosa and species of Staphylococcus have also been isolated from UTI cases. However, underlying host factors such as patient's age and gender may influence the prevalence of the causative agents $[10,11]$. Because the prevalence of uropathogens may vary with the age and geographic location, knowledge of local prevailing pathogens is necessary to guide disease management.

Several risk factors including age, gender, fever, constipation, uncircumcision, lack of toilet training, bladder instability, infrequent voiding of urine, previous antibiotic use, vesicoureteral reflux, and presence of nitrates in urine have been associated with UTIs in the pediatric population [8, 12-14]. In addition to these factors, studies in developing countries have also reported poor hygiene, thread worm infections, and immunocompromised state as other risk factors [15]. A recent study in Taiwan demonstrated a significant association between the obesity and urinary tract infection in children [16]. Knowledge of risk factors is necessary to reduce morbidity since UTI will be promptly diagnosed and managed. Because children with UTIs usually present with nonspecific signs and symptoms, the laboratory investigation is imperative as UTI may often be missed on the history and physical examination. If not appropriately diagnosed and well managed, UTIs may become chronic and result in scaring of the kidney, causing hypertension and renal failure.

Management of the infection is becoming progressively complicated due to increasing resistance to antibiotics by etiologic agents, whereas the initial spread of resistant pathogens was in hospital settings, and resistant pathogens have emerged in community-onset UTIs [17]. Knowledge of the regional antibiotic resistance is necessary to guide empiric therapy, particularly in resource poor settings where there are no facilities for culture and antibiotic susceptibility testing.

The evolving state of knowledge about pediatric UTI leaves many questions and controversies with a major concern being the risk factors associated with these infections. Little attention has been paid to this small but growing problem worldwide and in Cameroon. While mortality rates are not usually high, the economic burden is substantial [2]. Very few studies in Cameroon have addressed UTI in the pediatric population. Motse et al. [8] identified factors associated with UTI and their diagnostic performances in children under 5 in Douala, Cameroon. Akoachere et al. [17] investigated the etiologic profile and antibiotic susceptibility of community-acquired UTI in participants of all groups. The aim of the present study was to investigate the risk factors and etiologic agents of UTI and their susceptibility in the pediatric population (children $\leq 15$ years) in Buea. Findings will enhance UTI prevention, diagnosis, and management in the pediatric population in the study area.

\section{Materials and Methods}

2.1. Study Area and Design. The study was carried out in Buea, the capital city of South West Region, Cameroon. Buea is located on the eastern slopes of Mount Cameroon. It has tropical and mountain rainforest as well as savannah vegetation. The climate is humid with extended periods of rainfall, characterized by incessant drizzle and damp fogs common during the rainy season. Buea has a fast-growing population of over 200,000 inhabitants of which about $25 \%$ of the population is made up of children aged 15 years and below.

In a cross-sectional case-control laboratory investigation with participants drawn from two health facilities (Regional Hospital and Solidarity Clinic, Buea) and the community, urine samples from children $\leq 15$ years of age presenting with symptoms of UTI (cases) and sex- and age-matched children without symptoms suggestive of UTI (controls) were analyzed to determine the predictors of UTI and their the antibiotic susceptibility. Questionnaires were administered to participants or their parents/guardians to obtain information on demographic characteristics, symptoms, and risk factors.

Those with urinary abnormalities, chronic illness, or had been on antibiotic treatment 7 days prior to the sample collection were excluded. For the control group, age- and sexmatched children with no symptoms of UTI who gave assent and parent/guardian gave consent were recruited.

2.2. Sample Size Calculation. The sample size was calculated using the single population proportion formula of Kish [18]. A prevalence of UTI of $13.8 \%$ reported in a similar population [19] was used. The calculated minimum sample size was 182.8 . We included 200 cases and 205 controls giving an overall population of 405 .

2.3. Sample Collection. The method used for the sample collection depended on the age of the participant [20]. For younger children (1-3 years old), samples were collected by suprapubic aspiration while clean-catch midstream samples were collected from older participants. Suprapubic aspiration was done by trained medical personnel.

Older females were asked to sit on the toilet pot, wash their genitalia with clean water, separate the labia, and then pass out some amount of urine before placing the container to collect the midstream sample. Males were instructed to wash their genitalia and pass out some quantity of urine into the toilet before placing the container to collect the sample. Samples were collected in sterile, dry, wide-mouth, leakproof container, clearly labelled, and then transported to the Microbiology Laboratory at the Faculty of Health Sciences, University of Buea, for analysis.

2.4. Questionnaire. A pretested questionnaire was administered to all participants to obtain information on demographics, symptoms, and risk factors. Information concerning risk factors like kidney infection and kidney anomaly were obtained from the participant's medical report. 
TABle 1: Microscopy (wet mount) of sample.

\begin{tabular}{|c|c|c|c|c|c|}
\hline Cells & Sample group & $<5 / \mathrm{HPF}$ & $\begin{array}{c}\text { Positive samples (\%) } \\
\geq 5 / \mathrm{HPF}\end{array}$ & Total & $\begin{array}{l}\text { Statistics } \\
\text { df, } F, P\end{array}$ \\
\hline \multirow{3}{*}{ Leucocytes/pus } & Test group & $30(42.9)$ & 40 (57.1) (pyuria) & $70(35)$ & \multirow{3}{*}{$2,0.78,0.031$} \\
\hline & Control & $21(100)$ & $0(0.0)$ & $21(10.2)$ & \\
\hline & 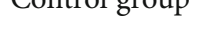 & $<10 / \mathrm{HPF}$ & $\geq 10 / \mathrm{HPF}$ & Total (\%) & \\
\hline \multirow{2}{*}{ Bacteria cells } & Test group & $83(79)$ & $22(21)$ & $105(52.5)$ & \multirow{2}{*}{$2,0.81,0.009$} \\
\hline & Control group & $34(100)$ & $0(0.0)$ & $34(16.6)$ & \\
\hline \multirow{2}{*}{ RBCs } & Test group & $20(69)$ & $9(31)$ & $29(14.5)$ & \multirow{2}{*}{$2,0.41,0.314$} \\
\hline & Control group & $0(0.0)$ & $0(0.0)$ & $0(0.0)$ & \\
\hline \multirow{2}{*}{ Epithelial cells } & Test group & $109(84.5)$ & $20(15.5)$ & $129(64.5)$ & \multirow{2}{*}{$2,0.73,0.048$} \\
\hline & Control group & $100(100)$ & $0(0.0)$ & $100(48.8)$ & \\
\hline \multirow{2}{*}{ Schistosoma haematobium } & Test group & & & $1(0.5)$ & \multirow{2}{*}{$2,0.344,0.782$} \\
\hline & Control group & & & $0(0.0)$ & \\
\hline \multirow{2}{*}{ Trichomonas vaginalis } & Test group & & & $1(0.5)$ & \multirow{2}{*}{$2,0.208,0.823$} \\
\hline & Control group & & & $0(0.0)$ & \\
\hline \multirow{2}{*}{ Yeast cells } & Test group & & & $12(6.0)$ & \multirow{2}{*}{$2,0.798,0.058$} \\
\hline & Control group & & & $1(0.5)$ & \\
\hline
\end{tabular}

N/B: RBCs: red blood cells; HPF: high power Field.

2.5. Microscopic Examination of Samples. Ten milliliters $(10 \mathrm{ml})$ of sample was centrifuged at $2000 \mathrm{rpm}$ for 5 minutes and the sediments mounted on a clean slide and observed under a microscope using a $\times 40$ objective. Samples were observed for the presence of bacteria, pathogenic parasites, and other pathological indicators like crystals and epithelial cells. The wet mount was flooded with iodine to enhance visibility especially of the ova or cysts of parasites and yeast cells [20]. Microscopy which revealed at least 5 white blood cells per high power field (HPF) and/or the presence of bacteria cells and/or yeast or parasites per HPF was suggestive of UTI [21] (Table 1).

2.6. Isolation and Identification of Bacteria. Samples were thoroughly mixed and cultured as described by Ibeneme et al. [21]. Sample was inoculated onto Cysteine Lactose Electrolyte Deficient (CLED) agar (Neogen Corp., Lansing USA) and incubated aerobically at $37^{\circ} \mathrm{C}$ for 24 hours after which cultures were observed for growth. A pure growth with counts of $\geq 10^{5} \mathrm{CFU} / \mathrm{mL}$ for midstream samples or growth of any number of uropathogens from suprapubic samples were considered as significant. Isolated colonies from pure culture plates were subjected to identification based on colonial characters and biochemical tests. The tests carried out were Gram staining, oxidase test, catalase test, coagulase test, growth on Mannitol Salt Agar (for Gram-positive cocci), and Triple Sugar Iron Agar (Laboratories Pronadisa CONDA, S.A) for primary identification. The API 20E (Biomérieux SA, France) kit was used to confirm the identity of Enterobacteriaceae.

2.7. Antimicrobial Susceptibility Testing. The disc diffusion technique was used to study the antibiotic susceptibility of isolates according to the recommendations of the Clinical Laboratory Standards Institute (CLSI) [22]. The following antibiotics were analyzed: trimethoprim-sulphamethoxazole
$(1.25 / 23.75 \mu \mathrm{g})$, ampicillin $(10 \mu \mathrm{g})$, ceftriazone $(30 \mu \mathrm{g})$, amoxicillin/clavulanic acid $(30 \mu \mathrm{g})$, nitrofurantoin $(300 \mu \mathrm{g})$, and cefadroxil $(30 \mu \mathrm{g})$. These are among the antibiotics recommended by the WHO [23] for the treatment of UTIs in children. Antibiotic discs were placed on inoculated Mueller-Hinton agar (Biotech. Lab. LTD, Suffulk, UK) plates and incubated for $18 \mathrm{~h}$ at $37^{\circ} \mathrm{C}$. After the incubation period, zones of inhibition were measured to the nearest millimeters. The results were interpreted according to the Clinical and Laboratory Standards Institute [22].

2.8. Ethical Considerations. This study was approved by the Faculty of Health Sciences Institutional Review Board (IRB), University of Buea. An administrative clearance was obtained from the Delegation of Public Health for the South West Region and also from participating health facilities. An informed consent was obtained from parents/guardians and assent (for older children) before collection of urine specimens.

2.9. Statistical Analysis. Data obtained was entered into Micro Soft Excel and exported to the software package STATA 10. Means were used for continuous variables like age while proportions were used for categorical variables like sex, presence, or absence of infection. Odds ratios and bivariate and multivariate analyses were used to assess relationships between predictors (such as symptoms and risk factors) and urinary tract infections. $P<0.05$ was considered significant.

\section{Results}

3.1. Characteristics of the Study Population. A total of 405 children (200 cases and 205 controls) were enrolled in this study (Table 2). The mean age of participants was 8.17 years (range 1 to 15 years). They were divided into three age 
TABLe 2: Demographic and clinical characteristics of study participants.

\begin{tabular}{|c|c|c|c|}
\hline Characteristics & & Case group (\%) & Control group (\%) \\
\hline \multicolumn{4}{|l|}{ Demographic } \\
\hline \multirow{3}{*}{ Gender } & Male & $97(48.5)$ & $100(48.8)$ \\
\hline & Female & $103(51.5)$ & $105(51.2)$ \\
\hline & Total & 200 & 205 \\
\hline \multirow{4}{*}{ Age (years) } & $1-5$ & $52(26)$ & $45(22.0)$ \\
\hline & $6-10$ & $95(47.5)$ & $99(48.3)$ \\
\hline & $11-15$ & $53(26.5)$ & $61(29.8)$ \\
\hline & Total & 200 & 205 \\
\hline \multicolumn{4}{|l|}{ Clinical } \\
\hline \multirow{7}{*}{ Specific symptoms } & Frequent urination & $158(79)$ & NA \\
\hline & Dysuria & $49(24.5)$ & NA \\
\hline & Hematuria & $11(5.5)$ & NA \\
\hline & Urgency & $52(26)$ & NA \\
\hline & Nocturia & $126(63)$ & NA \\
\hline & Incontinence & $68(34)$ & NA \\
\hline & Backpain & $24(12)$ & NA \\
\hline \multirow{8}{*}{ Nonspecific symptoms } & Fever & $124(62)$ & NA \\
\hline & Vomiting & $78(39)$ & NA \\
\hline & Diarrhea & $37(18.5)$ & NA \\
\hline & Abdominal pain & $71(35.5)$ & NA \\
\hline & Flank pain & $23(11.5)$ & NA \\
\hline & Headache & $92(46)$ & NA \\
\hline & Nausea* & $14(7)$ & NA \\
\hline & Anorexia & $13(6.5)$ & NA \\
\hline
\end{tabular}

NA: not applicable. ${ }^{*}$ Participants who reported the presence of this symptom were those $>5$ years old.

groups: $\leq 5$ years, $6-10$ years, and $11-15$ years. Majority of the participants were in the age group 6-10 years. For the specific symptoms, the majority of cases reported frequent urination (79\%) followed by nocturia (63\%). The predominant nonspecific symptoms observed in cases were fever $(62 \%)$, headache (42\%), vomiting $(39 \%$,$) and abdominal pain (35.5 \%)$ (Table 2). The common risk factor observed among participants was incontinence $(32 \%)$ while catheterization $(0.5 \%)$ was the least observed. Most of these factors were more common in cases than in controls (Table 3).

3.2. Microscopy of Urine Samples. Of the 200 cases, bacteriuria was detected in 105 (52.5\%). Of these, 22 (21\%) had significant counts $(\geq 10 / \mathrm{HPF})$. Erythrocytes were detected in 29 samples of which 9 (31\%) had significant erythrocyte count. Of the $129(64.5 \%)$ samples in which epithelial cells were detected, counts were significant in 20 (15.5\%) samples. Leucocytes were detected in $70(35 \%)$ cases but significant pyuria ( $\geq 5$ leukocytes/HPF) occurred in 40 (57.1\%) (Table 1$)$. Thus, these $40(40 / 200,20 \%)$ samples were presumptively diagnosed with UTI. For the control group, no sample reported significant bacteriuria or pyuria. However, 21 (10.2\%) of them had $<5$ leukocytes/HPF.

Microscopy also revealed the presence of parasitic organisms and yeast in some samples. Trichomonas vaginalis
$(0.5 \%)$ and Schistosoma haematobium $(0.5 \%)$ were parasitic organisms detected. Yeast cells were found in 12 (6\%) samples from cases and $1(0.5 \%)$ control sample. Of the 14 cases with parasitic infections, $12(6 \%)$ were coinfections with bacteriuria. The prevalence of UTI in our study based on microscopy was $12 \%(24 / 200)$.

3.3. Urine Culture. Bacterial growth was found in 105 (52.5\%) case samples, of which $34(32.4 \%)$ had counts of $>10^{5} \mathrm{CFU} / \mathrm{ml}$. None of the control samples had significant bacterial growth. Significant growth was recorded in 18 (9\%) males and 16 (8\%) females. This difference was not significant at $\mathrm{P}=0.385$ (Table 4$)$. Bacterial growth was significantly more in older children $(F=0.82, P=0.048)$, with the most growth (35.8\%) in participants $11-15$ years old. Bacterial growth was significantly associated with bacteriuria results obtained by microscopy at $P=0.003$.

Escherichia coli (39.4\%), Staphylococcus aureus (26.3\%), and Pseudomonas aeruginosa (14.1\%) were the most frequently isolated organisms. Other bacteria isolated were Klebsiella oxytoca (2.0\%), Klebsiella pneumoniae, Providencia alcalifaciens, Serratia rubidaea, Pantoea spp, and Aeromonas salmonicida each with a frequency of isolation of $1.0 \%$ (Figure 1). 
TABLE 3: Risk factors observed among participants.

\begin{tabular}{|c|c|c|c|c|c|}
\hline Risk factor & $\begin{array}{l}\text { No. of test cases } \\
\quad(n=200)\end{array}$ & $\%$ & $\begin{array}{l}\text { No. of control subjects } \\
(n=205)\end{array}$ & $\%$ & $\begin{array}{c}\text { Bivariate analysis } \\
P, \mathrm{ORs}\end{array}$ \\
\hline Previous UTIs & 19 & 9.5 & 20 & 9.8 & $0.633,0.34$ \\
\hline Frequency $>2 /$ year & 10 & 5.0 & 7 & 3.4 & $0.434,1.55$ \\
\hline Kidney infection & 2 & 1.0 & 2 & 1.0 & $0.742,0.11$ \\
\hline Kidney anomaly & 4 & 2.0 & 3 & 1.5 & $0.812,1.28$ \\
\hline Noncircumcision & 13 & 6.5 & 9 & 4.4 & $0.675,0.88$ \\
\hline Catheterization & 1 & 0.5 & 1 & 0.5 & $0.987,0.21$ \\
\hline Incontinence & 68 & 34.0 & 73 & 35.6 & $0.098,0.78$ \\
\hline
\end{tabular}

TABLe 4: Prevalence of UTI in study participants following analysis of samples by culture.

\begin{tabular}{|c|c|c|c|c|}
\hline Characteristic & Sample group & Total & Positive $(\%) \geq 10^{5} \mathrm{CFU} / \mathrm{ml}$ & Negative $(\%)<10^{5} \mathrm{CFU} / \mathrm{ml}$ \\
\hline \multicolumn{5}{|l|}{ Sex } \\
\hline \multirow{2}{*}{ Males } & Test group & 97 & $18(18.6)$ & $79(81.4)$ \\
\hline & Control group & 100 & $0(0.0)$ & $100(100)$ \\
\hline \multirow{2}{*}{ Females } & Test group & 103 & $16(15.5)$ & $87(84.5)$ \\
\hline & Control group & 105 & $0(0.0)$ & $105(100)$ \\
\hline \multirow{2}{*}{ Total } & Test group & 200 & $34(17)$ & $166(83.0)$ \\
\hline & Control group & 205 & $0(0.0)$ & $205(100)$ \\
\hline \multicolumn{5}{|l|}{ Age } \\
\hline \multirow{2}{*}{$1-5$} & Test group & 52 & $5(9.6)$ & $47(90.4)$ \\
\hline & Control group & 55 & $0(0)$ & $55(100)$ \\
\hline \multirow{2}{*}{$6-10$} & Test group & 95 & $10(10.5)$ & $85(89.5 \%)$ \\
\hline & Control group & 105 & $0(0)$ & $105(100)$ \\
\hline \multirow{2}{*}{$11-15$} & Test group & 53 & $19(35.8)$ & $34(64.2)$ \\
\hline & Control group & 53 & $0(0)$ & $53(100)$ \\
\hline \multirow{2}{*}{ Total } & Test group & 200 & $34(17)$ & $166(83)$ \\
\hline & Control group & 205 & $0(0)$ & $205(100)$ \\
\hline
\end{tabular}

Sex: $\mathrm{df}=1, F=0.76, P=0.385$; age: $F=0.82, P=0.048$.

The prevalence of $E$. coli was significantly higher in females $(32.3 \%)$ following bivariate $(F=19.02 ; P=0.001)$ and multivariate $(t=8.63, P=0.001)$ regression analyses. $P$. aeruginosa was higher in females $(11.1 \%)$ though the difference was not significant $(F=0.76 ; P=0.3846)$. Serratia rubidaea, Klebsiella oxytoca, and Klebsiella pneumoniae were isolated only from males while Aeromonas salmonicida, Pantoea spp, Providencia alcalifaciens, and Enterobacter cloacae were isolated only from females.

The distribution of these bacteria was found to vary with gender.

3.4. Predictors of UTI. Amongst the specific symptoms reported by participants, only urinary urgency $(F=4.98, P$ $=0.027)$ and back pain $(F=12.37, P=0.001)$ were significantly associated with UTIs after bivariate analysis. A multivariate analysis of these symptoms also gave significant association: urinary urgency $(t=-2.10, P=0.037)$; back pain $(t=3.04, P=0.003)$ (Table 5). None of the nonspecific symptoms showed a significant association with UTI. However, fever was reported in a majority $(124,62 \%)$ of study cases, and all $22(11 \%)$ cases with significant bacteriuria were febrile.

Other factors investigated were age, sex, previous UTIs, frequency of occurrence $\geq$ twice/year, kidney infection, kidney anomaly, noncircumcision of males, catheterization, and incontinence.. Investigating the association between these factors and UTI, kidney anomaly $(P=0.669, \mathrm{OR}=$ $3.28, \mathrm{CI}=0.25,43.45)$ and frequency $>2$ /year $(P=0.203$, $\mathrm{OR}=2.64, \mathrm{CI}=0.59,11.75)$ had greater odds of association with UTI amongst the test cases. However, there was no statistically significant difference from the controls (Table 6).

3.5. Antibiotic Sensitivity of Isolates. Overall, ceftriazone (90.1\%) was the most active antibiotic, followed by cefadroxil (80.5\%) and sulfamethoxazole/trimethoprim (79.3\%) (Table 7). All isolates were sensitive to ceftriazone (100\%) except some strains of $E$. coli, $S$. aureus, and $P$. aeruginosa which had resistance or intermediate activity. There was no isolate with $100 \%$ susceptibility to all drugs tested. However, some strains of Streptococcus spp, Proteus vulgaris, Enterobacter cloacae, Providencia alcalifaciens, and Serratia 


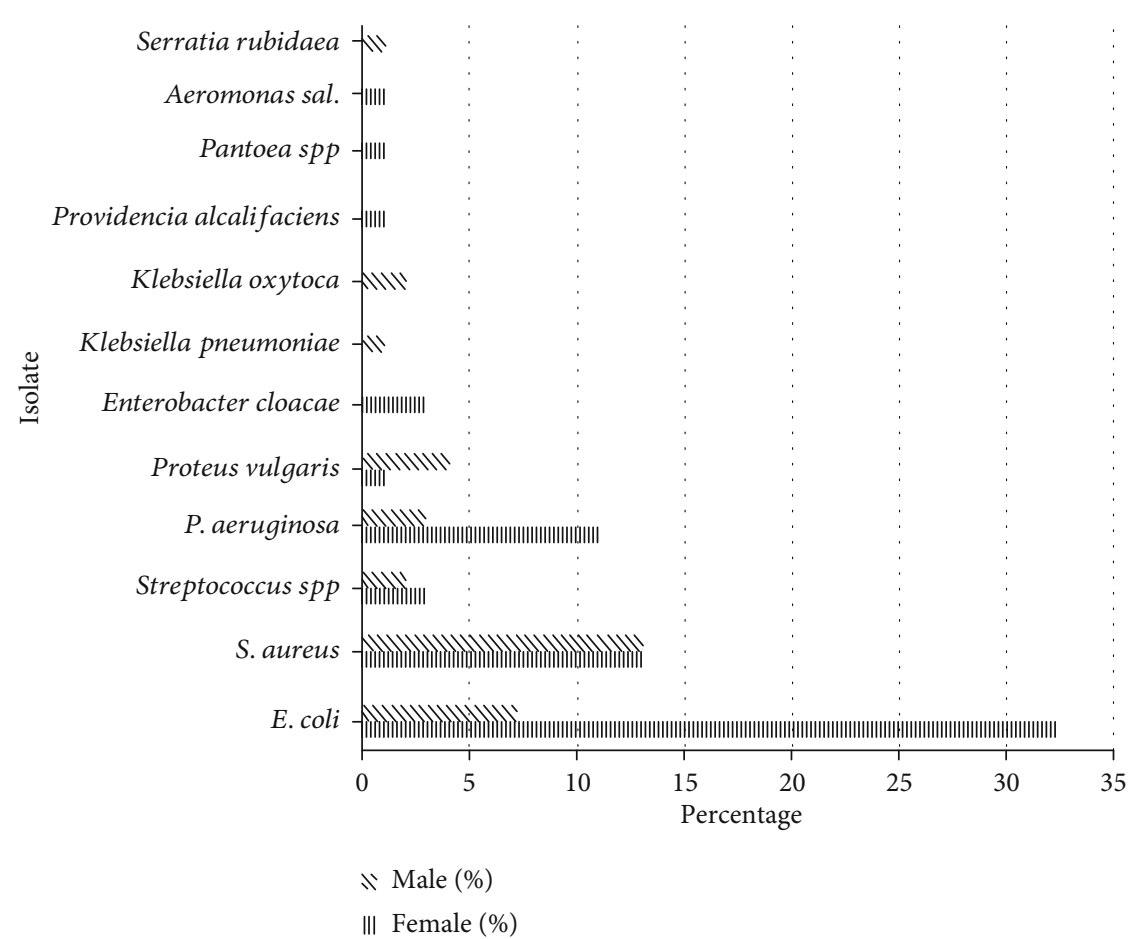

FIGURE 1: Bacteria uropathogens isolated and their distribution with respect to gender.

rubidaea showed $100 \%$ resistance to certain drugs. None of the predominant isolates (E. coli and $S$. aureus) showed $100 \%$ susceptibility to any of the drugs tested except sulfamethoxazole/trimethoprim on S. aureus. However, the overall susceptibility of $S$. aureus (68\%) was higher than that of $E$. coli $(58.1 \%)$. Ampicillin (40.5\%) was the least active antibiotic (Table 7). Isolates were most resistant to nitrofurantoin $(26.6 \%)$ followed by ampicillin (25.2\%). With the exception of $E$. coli, all isolates had at least one drug to which they showed $100 \%$ susceptibility.

\section{Discussion}

Urinary tract infections are a common and an important clinical problem in childhood. UTI is a common cause of morbidity in children and if not diagnosed early and treated, it could result in long-term complications [24]. However, most children with UTI tend to present with fever, and this makes it difficult to distinguish UTI from other febrile illnesses on clinical grounds [25]. The goal should be to identify at-risk patients so as to put in place preventive measures against UTIs in children. Our study investigated the predictors of these UTIs in children $\leq 15$ years presenting at two hospitals in Buea, the etiologic agents, and the possible antimicrobials necessary for their management.

Leukocytes were detected in 70 (35\%) samples from cases of which $40(57.1 \%)$ had significant pyuria ( $\geq 5$ leukocytes/HPF) (Table 3). This indicates possible UTI. Other factors like presence of erythrocytes or bacteria cells are also considered in the case where pyuria is absent. However, the diagnosis of a UTI is primarily defined by the detection of the pathogen in urine [26]. Significant hematuria was detected in $9(31 \%)$ samples from cases. Hematuria could be due to haemorrhage, inflammation necrosis, or trauma in the urinary system. Schistosoma haematobium which abrades the walls of the urinary tract causing bleeding was found in one of the samples with hematuria. Twenty (15.5\%) (Table 1) case samples had epithelial cells with counts $\geq 10 / \mathrm{HPF}$. It is believed that a large number of epithelial cells in urine result from inflammation of the urinary tract [20]. The nonbacterial pathogens which were detected by microscopy include Schistosoma haematobium (0.5\%), T. vaginalis, (0.5) and yeast cells (6\%) though their prevalence was low. T. vaginalis was detected in a 15 -year-old female. $T$. vaginalis is a sexually transmitted infection. Apart from genital specimens, it can be detected in urine. The presence of this protozoan in our study participant could have been due to an STI rather than UTI given that some children-especially girls-become sexually active before the age of 15 years. We did not proceed to differentiate the types of yeasts. Our findings show that parasitic organisms may not be a major cause of UTI in children in the study area, compared to yeast and bacteria. It should be noted that school children or adolescents can be further exposed due to poor hygienic and sanitation in the school environment.

Only 34 out of 200 (17\%) were confirmed with UTI by culture. Urine culture is definitive for diagnosis of UTIs but takes 2 to 3 days. However, microscopy is a reliable diagnostic tool in resource-poor settings such as our study area, where there are no culture facilities. There are newer technologies which could improve UTI diagnosis and management via direct pathogen detection from urine samples, rapid antimicrobial susceptibility testing, and point-of-care testing but most diagnostic laboratories cannot afford these new technologies [27]. 
TABLE 5: Relationship of clinical characteristics investigated and occurrence of UTI.

\begin{tabular}{|c|c|c|c|c|c|}
\hline Question & Response & $\begin{array}{c}\text { Count } \\
(n)\end{array}$ & $\begin{array}{l}\text { Frequency } \\
(\%)\end{array}$ & $\begin{array}{c}\text { Bivariate analysis } \\
F \text { value, } \\
P \text { value }\end{array}$ & $\begin{array}{l}\text { Multivariate analysis } \\
\text { (t value, } P \text { value) }\end{array}$ \\
\hline \multicolumn{6}{|l|}{ Specific symptoms } \\
\hline \multirow{2}{*}{ Frequency } & Yes & 158 & 79 & \multirow{2}{*}{$0.19,0.661$} & \multirow{2}{*}{ ND } \\
\hline & No & 42 & 21 & & \\
\hline \multirow{2}{*}{ Dysuria } & Yes & 49 & 24.5 & \multirow{2}{*}{$1.00,0.319$} & \multirow{2}{*}{ ND } \\
\hline & No & 151 & 75.5 & & \\
\hline \multirow{2}{*}{ Hematuria } & Yes & 11 & 5.5 & \multirow{2}{*}{$3.11,0.079$} & \multirow{2}{*}{ ND } \\
\hline & No & 189 & 94.5 & & \\
\hline \multirow{2}{*}{ Urgency } & Yes & 52 & 26 & \multirow{2}{*}{$4.98,0.027$} & \multirow{2}{*}{$-2.10,0.037$} \\
\hline & No & 148 & 74 & & \\
\hline \multirow{2}{*}{ Nocturia } & Yes & 126 & 63 & \multirow{2}{*}{$0.03,0.871$} & \multirow{2}{*}{ ND } \\
\hline & No & 74 & 37 & & \\
\hline \multirow{2}{*}{ Incontinence } & Yes & 68 & 34 & \multirow{2}{*}{$0.02,0.880$} & \multirow{2}{*}{ ND } \\
\hline & No & 132 & 66 & & \\
\hline \multirow{2}{*}{ Back pain } & Yes & 24 & 12 & \multirow{2}{*}{$12.37,0.001$} & \multirow{2}{*}{$3.04,0.003$} \\
\hline & No & 176 & 88 & & \\
\hline \multicolumn{6}{|l|}{ Nonspecific symptoms } \\
\hline \multirow{2}{*}{ Fever } & Yes & 124 & 62 & \multirow{2}{*}{$0.00,0.975$} & \multirow{2}{*}{ ND } \\
\hline & No & 76 & 38 & & \\
\hline \multirow{2}{*}{ Vomiting } & Yes & 78 & 39 & \multirow{2}{*}{$2.45,0.119$} & ND \\
\hline & No & 122 & 61 & & ND \\
\hline Diarrhea & Yes & 37 & 18.5 & 1720104 & \\
\hline Diarmea & No & 163 & 81.5 & $1.72,0.194$ & ND \\
\hline A l d & Yes & 71 & 35.5 & $0=70450$ & (חי \\
\hline Abdominal pain & No & 129 & 64.5 & $0.5 \%, 0.453$ & ND \\
\hline Cloln & Yes & 23 & 11.5 & 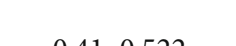 & NDP \\
\hline Flank pain & No & 177 & 88.5 & $0.41,0.522$ & ND \\
\hline Headache & Yes & 92 & 46 & $006 \quad 0811$ & ND \\
\hline Healuacile & No & 108 & 54 & $0.00,0.011$ & NDD \\
\hline Naucen & Yes & 14 & 7 & 0730397 & ND \\
\hline Naused & No & 186 & 93 & $0.17,0.592$ & ND \\
\hline Anorovis & Yes & 13 & 6.5 & $003 \quad 0870$ & ND \\
\hline Anorexia & No & 187 & 93.5 & $0.00,0.8 / 0$ & ND \\
\hline & $\leq$ one week & 171 & 85.5 & & \\
\hline Duration of symptoms/ & $>$ one week and $<$ one month & 26 & 13 & $0.11,0.741$ & ND \\
\hline & $\geq$ one month & 3 & 1.5 & & \\
\hline
\end{tabular}

Twenty-two out of 200 participants had bacteriuria. Non-bacterial pathogens were detected in 14 (7\%) test cases of which $12(6 \%)$ were co-infections with bacteriuria. Therefore, 24 out of 200 test cases (12\%) had UTIs by microscopy, giving a UTI prevalence of $12 \%$. Our prevalence is higher than $11 \%$ recently reported in children under 5 in Nigeria [21] but lower than $32.2 \%$ reported in a recent study of children under 5 in Douala, Cameroon [8], and 65.9\% reported in Buea [17]. Though the prevalence of UTI in our study is relatively low, it is still a cause for concern given that if not promptly diagnosed and adequately treated, it could result in chronic ill health and long-term renal damage. The occurrence of these infections in children is of prime importance since they have developing kidneys which are more susceptible to be damaged by pyelonephritis.

Contrary to the report from Douala [8] and elsewhere $[21,28]$ in which females were more at risk than males, our study observed a higher prevalence in males than in females though the difference was not significant. Poor hygiene generally observed with male children must have accounted for this observation.

The majority of bacterial agents associated with UTIs were Gram-negative (68.6\%) enteric bacteria (Figure 1). E. coli $(39.4 \%)$ was the most frequently isolated followed by $S$. aureus $(26.3 \%)$ and $P$. aeruginosa (14.1\%). E. coli has been documented by several studies as a leading cause 
TABLE 6: Association of risk factors with urinary tract infection.

\begin{tabular}{|c|c|c|c|}
\hline Risk factors & Positive UTI cases $(\%)$ & $\begin{array}{l}\text { Bivariate analysis } \\
P, \text { ORs }(95 \% \mathrm{CI})\end{array}$ & $\begin{array}{l}\text { Multivariate analysis } \\
(t \text { value, } P \text { value })\end{array}$ \\
\hline \multicolumn{4}{|l|}{ Age } \\
\hline $1-5(n=52)$ & $5(9.6)$ & \multirow{3}{*}{$0.777,0.68(0.51,2.41)$} & \multirow{3}{*}{ ND } \\
\hline $6-10(n=95)$ & $22(23.2)$ & & \\
\hline $11-15(n=53)$ & $7(13.2)$ & & \\
\hline \multicolumn{4}{|l|}{ Sex } \\
\hline Male $(n=97)$ & $18(18.6)$ & \multirow{2}{*}{$0.385,1.30(0.33,5.13)$} & \multirow{2}{*}{ ND } \\
\hline Female $(n=103)$ & $16(15.5)$ & & \\
\hline Previous UTIs, $n=19$ & $3(15.8)$ & $0.311,1.25(0.81,1.93)$ & ND \\
\hline Frequency $>2$ /year, $n=10$ & $1(10)$ & $0.203,2.64(0.59,11.75)$ & ND \\
\hline Kidney infection, $n=2$ & $1(50)$ & $0.289,0.22(0.01,3.61)$ & ND \\
\hline Kidney anomaly, $n=4$ & $1(25)$ & $0.669,3.28(0.25,43.45)$ & ND \\
\hline Noncircumcision, $n=13$ & $4(30.8)$ & $0.191,0.35(0.08,1.45)$ & ND \\
\hline Catheterization, $n=1$ & $0(0.0)$ & $0.421,0.23(0.07,12.1)$ & ND \\
\hline Incontinence, $n=68$ & $11(16.2)$ & $0.880,0.93(0.41,2.18)$ & ND \\
\hline
\end{tabular}

NB: NA: not applicable; ND: not determined.

of bacterial UTIs in the pediatric population [8, 9, 11, 29]. These studies isolated similar uropathogens as those detected in our study. Other studies have reported $P$. aeruginosa as a major cause of UTI in pediatrics [30]. The prevalence of E. coli (32.3\%) and P. aeruginosa $(11.1 \%)$ was higher in females than in males (Figure 1). Similar to Saperston et al. and Naseri and Tafazoli [11, 31], gender disparity for $E$. coli was significant $(\mathrm{df}=1, F=19.02$, $P=0.001)$ in pediatric patients while that for $P$. aeruginosa was negligible $(\mathrm{df}=1, F=0.76, P=0.3846)$. The high prevalence of $E$. coli in females reported in our study contradicts the report of Ali et al. [32] who detected a higher prevalence in males than in females. Similar to the findings of Akoachere et al. [17], $P$. aeruginosa was isolated more from females than males. The second most prevalent isolate, $S$. aureus, showed an equal prevalence in females as in males. The significance of the urinary tract infection with Staphylococci in pediatric patients has been recognized by studies from other developing countries [25, 33]. S. aureus is an uncommon cause of pediatric UTI and has been associated with urinary malformations [34]. Although Staphylococcus aureus has been considered pathogenic, coagulase positive staphylococci were often interpreted as genital or skin contaminants or colonizers [31].

The clinical significance of some of the less frequently isolated bacterial pathogens in urinary tract infections such as Aeromonas salmonicida and Pantoea spp has not been very much investigated. A. salmonicida, though a causative agent of furunculosis, a bacterial septicaemia of salmon fish, has been isolated from a patient with UTI [35]. Pantoea spp has generally been associated with plants [36]; however, Cruz et al. [37] isolated one of its species, Pantoea agglomerans, from children with UTI.

Specific symptoms reported by participants were frequent urination, dysuria, hematuria, urgency, nocturia, incontinence, and back pain. Only urgency and back pain were significantly associated with UTI following bivariate (urgency; $F=4.98, P=0.027$, back pain; $F=12.37, P=$ 0.001 ) and multivariate (urgency; $t=-2.10, P=0.037$, back pain; $t=3.04, P=0.003$ ) analyses (Table 5), and these could be used to predict UTI in children in our study area. No nonspecific symptom was significantly related to UTIs $(P>0.05)$ (Table 5). However, fever (62\%) was the most commonly reported nonspecific symptom. A wide range of other diseases could account for fever in children [38] apart from UTI.

Over the years, the risk factors associated with UTIs have been studied amongst adults. An adequate understanding of factors in the pediatric population is necessary for prevention, prompt diagnosis, and treatment. Among the risk factors investigated, kidney anomaly $(P=0.669, \mathrm{OR}=3.28$, $\mathrm{CI}=0.25,43.45)$ and frequency $>2 /$ year $(P=0.203, \mathrm{OR}=$ $2.64, \mathrm{CI}=0.59,11.75)$ showed higher odds of association with UTI. However, none of these associations were of statistical significance.

For empiric treatment to be successful, knowledge of local etiologic agents and their antibiotic susceptibility remains of prime importance. Our study investigated only antibiotics recommended by the WHO [23] for treatment of UTIs in children. Sensitivity ranged from $40.5 \%$ (ampicillin) to $90.1 \%$ (ceftriazone). High resistance to ampicillin has also been reported elsewhere [39]. The cephalosporins: cefriazone $(90.1 \%)$ and cefadroxil $(85.4 \%)$ had the best sensitivity and could be used for treatment. Ceftriazone (CRO) was the most efficient against all the isolates except for P. aeruginosa which had a sensitivity of $28.6 \%$ (Table 7 ) contradicting the report of Baral et al. [40] who reported a high level of resistance to cephalosporins. This confirms the fact that the susceptibility of uropathogens varies with time and location. Streptococcus spp showed $100 \%$ resistance to cefadroxil but had $100 \%$ susceptibility to other antibiotics studied.

The synergistic effect of the combined therapy drug regimen-trimethoprim/sulphamethoxazole was high in most of 
TABLE 7: Susceptibility of bacteria isolates to antibiotics commonly prescribed for treatment of the urinary infection in the pediatric population.

\begin{tabular}{|c|c|c|c|c|c|c|c|c|}
\hline \multirow[b]{2}{*}{ Organism (total) } & \multirow[b]{2}{*}{ Sensitivity } & \multicolumn{2}{|c|}{ Cephalosporins } & \multirow{2}{*}{$\begin{array}{c}\text { Nitrofurans } \\
\text { F } \\
(\%)\end{array}$} & \multirow{2}{*}{$\begin{array}{c}\text { Folate pathway } \\
\text { inhibitor } \\
\text { SXT } \\
(\%)\end{array}$} & \multirow{2}{*}{$\begin{array}{c}\beta \text {-Lactamase } \\
\text { inhibitor } \\
\text { AMC } \\
(\%)\end{array}$} & \multirow{2}{*}{$\begin{array}{l}\text { Penicillin A } \\
\text { AM } \\
(\%)\end{array}$} & \multirow[b]{2}{*}{$\begin{array}{c}\text { Overall } \\
\text { sensitivity (\%) }\end{array}$} \\
\hline & & $\begin{array}{c}\text { CRO } \\
(\%)\end{array}$ & CFR (\%) & & & & & \\
\hline \multirow{3}{*}{ E. coli, $n=39$} & $S$ & $23(58.9)$ & $31(79.5)$ & $27(69.2)$ & $20(51.3)$ & $27(69.2)$ & $8(20.5)$ & 58.1 \\
\hline & $\mathrm{I}$ & $4(10.3)$ & $6(15.8)$ & $12(30.8)$ & $19(48.7)$ & $11(28.2)$ & $1(2.6)$ & 22.7 \\
\hline & $\mathrm{R}$ & $12(30.8)$ & $2(4.7)$ & 0 & 0 & $1(2.6)$ & $30(76.9)$ & 19.2 \\
\hline \multirow{3}{*}{ S. aureus, $n=26$} & $S$ & $24(92.3)$ & $22(84.6)$ & $22(84.6)$ & $26(100.0)$ & $8(30.8)$ & $4(15.4)$ & 68.0 \\
\hline & $\mathrm{I}$ & $1(3.8)$ & $4(15.4)$ & $1(3.8)$ & 0 & $8(30.8)$ & 0 & 8.4 \\
\hline & $\mathrm{R}$ & $1(3.8)$ & 0 & $3(11.5)$ & 0 & $10(38.5)$ & $22(84.6)$ & 23.1 \\
\hline \multirow{3}{*}{ Streptococcus spp, $n=5$} & $\mathrm{~S}$ & $5(100.0)$ & 0 & $5(100.0)$ & $5(100.0)$ & $5(100.0)$ & $5(100.0)$ & 83.3 \\
\hline & I & 0 & 0 & 0 & 0 & 0 & 0 & 0.0 \\
\hline & $\mathrm{R}$ & 0 & $5(100.0)$ & 0 & 0 & 0 & 0 & 16.7 \\
\hline \multirow{3}{*}{$P$. aeruginosa, $n=14$} & $\mathrm{~S}$ & $4(28.6)$ & $14(100.0)$ & $11(78.6)$ & $14(100.0)$ & $7(50.0)$ & $7(50.0)$ & 67.9 \\
\hline & I & $8(57.1)$ & 0 & $2(14.3)$ & 0 & $4(28.6)$ & $6(42.7)$ & 23.8 \\
\hline & $\mathrm{R}$ & $2(14.3)$ & 0 & $1(7.1)$ & 0 & $3(21.4)$ & $1(7.1)$ & 8.3 \\
\hline \multirow{3}{*}{ P. vulgaris, $n=5$} & $S$ & $5(100.0)$ & $3(60.0)$ & $5(100.0)$ & $5(100.0)$ & $5(100.0)$ & 0 & 76.7 \\
\hline & I & 0 & $2(40.0)$ & 0 & 0 & 0 & 0 & 6.7 \\
\hline & $\mathrm{R}$ & 0 & 0 & 0 & 0 & 0 & $5(100.0)$ & 16.7 \\
\hline \multirow{3}{*}{ E. cloacae, $n=3$} & S & $3(100.0)$ & $3(100.0)$ & $3(100.0)$ & $3(100.0)$ & 0 & 0 & 66.7 \\
\hline & I & 0 & 0 & 0 & 0 & 0 & $2(66.7)$ & 11.1 \\
\hline & $\mathrm{R}$ & 0 & 0 & 0 & 0 & $3(100.0)$ & $1(33.3)$ & 22.2 \\
\hline \multirow{3}{*}{ K. pneumoniae, $n=1$} & S & $1(100.0)$ & $1(100.0)$ & 0 & $1(100.0)$ & 0 & 0 & 50.0 \\
\hline & I & 0 & 0 & $1(100.0)$ & 0 & $1(100.0)$ & $1(100.0)$ & 50.0 \\
\hline & $\mathrm{R}$ & 0 & 0 & 0 & 0 & 0 & 0 & 0.0 \\
\hline \multirow{3}{*}{ K. oxytoca, $n=2$} & S & $2(100.0)$ & $2(100.0)$ & 0 & $2(100.0)$ & 0 & 0 & 50.0 \\
\hline & I & 0 & 0 & $2(100.0)$ & 0 & $2(100.0)$ & $2(100.0)$ & 50.0 \\
\hline & $\mathrm{R}$ & 0 & 0 & & 0 & 0 & 0 & 0.0 \\
\hline \multirow{3}{*}{$\begin{array}{l}\text { Providencia } \\
\text { alcalifaciens, } n=1\end{array}$} & S & $1(100.0)$ & $1(100.0)$ & 0 & 0 & $1(100.0)$ & $1(100.0)$ & 66.7 \\
\hline & I & 0 & 0 & 0 & 0 & 0 & 0 & 0.0 \\
\hline & $\mathrm{R}$ & 0 & 0 & $1(100)$ & $1(100)$ & 0 & 0 & 33.3 \\
\hline \multirow{3}{*}{ Pantoea $\operatorname{spp}, n=1$} & S & $1(100.0)$ & $1(100.0)$ & 0 & 0 & $1(100.0)$ & $1(100.0)$ & 66.7 \\
\hline & I & 0 & 0 & 0 & 0 & 0 & 0 & 0.0 \\
\hline & $\mathrm{R}$ & 0 & 0 & $1(100.0)$ & $1(100.0)$ & 0 & 0 & 33.3 \\
\hline \multirow{3}{*}{ A. salmonicida, $n=1$} & S & $1(100.0)$ & $1(100.0)$ & $1(100)$ & $1(100.0)$ & $1(100.0)$ & 0 & 83.3 \\
\hline & I & 0 & 0 & 0 & 0 & 0 & $1(100.0)$ & 16.7 \\
\hline & $\mathrm{R}$ & 0 & 0 & 0 & 0 & 0 & 0 & 0.0 \\
\hline \multirow{3}{*}{ Serratia rub., $n=1$} & $S$ & $1(100.0)$ & $1(100.0)$ & 0 & $1(100.0)$ & $1(100.0)$ & $1(100.0)$ & 83.3 \\
\hline & I & 0 & 0 & 0 & 0 & 0 & 0 & 0.0 \\
\hline & $\mathrm{R}$ & 0 & 0 & $1(100.0)$ & 0 & 0 & 0 & 16.7 \\
\hline \multirow{3}{*}{ Total $=99$} & S & $71(90.1)$ & $80(85.4)$ & $74(52.7)$ & $78(79.3)$ & $56(62.5)$ & $28(40.5)$ & \\
\hline & I & $13(5.9)$ & $12(5.9)$ & $18(20.7)$ & $19(48.7)$ & $26(24.0)$ & $13(34.3)$ & \\
\hline & $\mathrm{R}$ & $15(4.1)$ & $7(8.7)$ & $7(26.6)$ & $2(16.7)$ & $17(13.5)$ & $61(25.2)$ & \\
\hline
\end{tabular}

N/B: S: sensitive; I: intermediate; R: resistant; AV.: average; CRO: ceftriazone; CFR: cefadroxil; F: nitrofurantoin; SXT: sulfamethoxazole-trimethoprim; AMC: amoxicillin-clavulanic acid; AM: ampicillin.

the isolates; however, an increasing rate of resistance to this drug has been reported in developing countries [39]. Of the 12 bacteria species isolated, 8 had $100 \%$ susceptibility to this drug. P. alcalifaciens and Pantoea spp were completely resis- tant. Amoxicillin/clavulanic acid showed no activity against E. cloacae, K. pneumoniae, and K. oxytoca. Amoxicillin/clavulanic acid has been recommended as first-line therapy for outpatient treatment of UTI in children [41]. Although we 
are reporting resistance to this drug in our study, a similar study elsewhere [42] has reported high activity (100\%) of this drug on uropathogens from the pediatric population. Unlike the other antibacterials, nitrofurantoin (52.7\%) and ampicillin (40.5\%) had the lowest overall activity. Contrary to our study, other reports have shown nitrofurantoin to have a higher sensitivity to uropathogens [40]. However, the effectiveness of nitrofurantoin in a patient is dependent on the time of administration; the longer the delay of administration from the time of infection, the less efficient the drug became [43].

\section{Conclusion}

E. coli was the predominant cause of UTI in our study. The symptoms, back pain and urinary urgency, were significantly associated with UTI in the study area and could be useful in predicting UTI in pediatric patients in the study area. The cephalosporines were the most active antibiotics, hence could be of value in the treatment of pediatric UTI.

This study provides baseline data which could help in the establishment of local guidelines for prediction and management of UTIs to avert complications that may arise due to UTI.

\section{Abbreviations \\ UTI: Urinary tract infection \\ CLED: Cyseine lactose electrolyte deficient \\ WHO: World Health Organisation \\ IRB: Institutional review board \\ HPF: High power field \\ WBC: White blood cell \\ CRO: Ceftriazone \\ CFR: Cefadroxil \\ F: Nitrofurantoin \\ SXT: Sulfamethoxazole-trimethoprim \\ AMC: Amoxicillin-clavulanic acid \\ AM: Ampicillin.}

\section{Data Availability}

All data generated or analyzed during this study are included in this article.

\section{Conflicts of Interest}

The authors declare that there is no conflict of interest regarding the publication of this paper.

\section{Acknowledgments}

We are grateful to the study participants and their parents/guardians for their contribution to this study. We are thankful to the management for authorising sample collection and to the staff for assisting in the sample collection.

\section{References}

[1] J. D. Spencer, A. Schwaderer, K. McHugh, and D. S. Hains, "Pediatric urinary tract infections: an analysis of hospitalizations, charges, and costs in the USA," Pediatric Nephrology, vol. 25, no. 12, pp. 2469-2475, 2010.

[2] A. Sood, F. J. Penna, S. Eleswarapu et al., "Incidence, admission rates, and economic burden of pediatric emergency department visits for urinary tract infection: data from the nationwide Emergency Department sample, 2006 to 2011," Journal of Pediatric Urology, vol. 11, no. 5, pp. 246.e1246.e8, 2015.

[3] E. Balighian and M. Burke, "Urinary tract infections in children," Pediatrics in Review, vol. 39, no. 1, pp. 3-12, 2018.

[4] R. T. Yobas, R. Tekin, S. Kelechi et al., "Community- acquired urinary tract infections in children: pathogens, antibiotic susceptibility and seasonal changes," European Review for Medical and Pharmacological Sciences, vol. 17, pp. 971976, 2013.

[5] D. A. Paduch, "Viral lower urinary tract infections," Current Urology Reports, vol. 8, no. 4, pp. 324-335, 2007.

[6] P. Behzadi, E. Behzadi, and R. Ranjbar, "Urinary tract infections and Candida albicans," Central European Journal of Urology, vol. 68, no. 1, pp. 96-101, 2015.

[7] N. Mor, U. Y. Tekdongan, and M. Bağcioğlu, "Parasitic diseases of urinary tract," Middle Black Sea Journal of Health Science, vol. 2, no. 3, pp. 13-20, 2016.

[8] D. F. K. Motse, G. P. Ngaba, L. P. K. Foko et al., "Predictors of urinary tract infection and their diagnostic performances among Cameroonian under," Journal of Infectious Diseases, vol. 9, no. 2, pp. 68-77, 2019.

[9] J. Kavitha, M. A. Aravind, G. Jayachandran, and S. Priya, "Risk factors for urinary tract infection in pediatric patients," International Journal of Contemporary Pediatrics, vol. 5, no. 1, pp. 184-189, 2017.

[10] E. Magliano, V. Grazioli, L. Deflorio et al., "Gender and AgeDependent etiology of Community-Acquired urinary tract infections," Scientific World Journal, vol. 2012, article 349597, 6 pages, 2012.

[11] M. Naseri and N. Tafazoli, "Etiologies of urinary tract infections in children considering differences in gender and type of infection," Journal of Paediatric Nephrology, vol. 5, no. 3, 2017.

[12] V. Kumar, A. George, and M. Viswanathakumar, "Study of clinical profile and risk factors associated with febrile urinary tract infection in preschool children," International Journal of Contemporary Pediatrics, vol. 3, no. 1, pp. 243246, 2016.

[13] R. H. Hanna-Wakim, S. T. Ghanem, M. W. el Helou et al., "Epidemiology and characteristics of urinary tract infections in children and adolescents," Frontiers in Cellular and Infection Microbiology, vol. 5, p. 45, 2015.

[14] O. G. Del Villar and K. B. Peña, "Urinary tract infections in pediatrics: clinical approach and follow up," Salud Uninorte Barranquilla (Colombia), vol. 34, no. 1, pp. 203-211, 2018.

[15] J. Ferdaus, G. Moinuddin, M. T. Islam, M. H. O. Rashid, M. R. Shawly, and A. Alim, "Risk factors of urinary tract infection in preschool children in Dhaka, Bangladesh," Bangladesh Medical Journal, vol. 45, no. 3, pp. 134-137, 2017.

[16] P. C. Hsu and S. J. Chen, "Obesity and risk of urinary tract infection in young children presenting with fever," Medicine, vol. 97, no. 49, article e13006, 2018. 
[17] J.-F. T. K. Akoachere, S. Yvonne, N. H. Akum, and E. N. Seraphine, "Etiologic profile and antimicrobial susceptibility of community-acquired urinary tract infection in two Cameroonian towns," BMC Research Notes, vol. 5, no. 1, p. 219, 2012.

[18] L. Kish, Survey sampling, John Wiley and Sons, Inc, New York, 1965.

[19] Anis-ur-Rehman, M. Jahanzeb, T. S. Siddiqui, and M. Idris, "Frequency and clinical presentation of UTI among children of Hazara Division, Pakistan," Journal of Ayub Medical College, Abbottabad : JAMC, vol. 20, no. 1, pp. 63-65, 2008.

[20] M. Cheesbrough, District Laboratory Practice in Tropical Countries, Cambridge University Press, 2nd edition, 2006.

[21] C. A. Ibeneme, T. Oguonu, H. U. Okafor, A. N. Ikefuna, and U. C. Ozumba, "Urinary tract infection in febrile under five children in Enugu, South Eastern Nigeria," Nigerian Journal of Clinical Practice, vol. 17, no. 5, pp. 624-628, 2014.

[22] Clinical Laboratory Standards Institute, "Performance standards for antimicrobial disk susceptibility testing," in Approved standard, vol. 34no. 1pp. 1-226, M02-A11, M07A9, and M11-A8CLSI, 2014.

[23] WHO, Laboratory Protocol: "Susceptibility testing of Enterobacteriaceae using disk diffusion", WHO Global Foodborne Infections Network, 2010.

[24] F. V. Lugg-Widger, L. Angel, R. Cannings-John et al., "Longterm outcomes of urinary tract infection (UTI) in Childhood (LUCI): protocol for an electronic record-linked cohort study," BMJ Open, vol. 9, no. 4, article e024210, 2019.

[25] F. Festo, R. K. Benson, H. Aldofina, and E. S. Mshana, "Predictors of urinary tract infection among febrile children attending at Bugando medical Centre north-western, Tanzania," Archives of Clinical Microbiology, vol. 2, no. 5, pp. 38233823, 2011.

[26] N. K. Biyikli, H. Alpay, E. Ozek, I. Akman, and H. Bilgen, "Neonatal urinary tract infections: analysis of the patients and recurrences," Pediatrics International, vol. 46, no. 1, pp. 21-25, 2004.

[27] M. Davenport, K. E. Mach, L. M. D. Shortliffe, N. Banaei, T. H. Wang, and J. C. Liao, "New and developing diagnostic technologies for urinary tract infections," Nature Reviews Urology, vol. 14, no. 5, pp. 296-310, 2017.

[28] R. Ganesh, D. Shrestha, B. Bhattachan, and G. Rai, "Epidemiology of urinary tract infection and antimicrobial resistance in a pediatric hospital in Nepal," BMC Infectious Diseases, vol. 19, no. 1, p. 420, 2019.

[29] A. K. C. Leung, A. H. C. Wong, A. A. M. Leung, and K. L. Hon, "Urinary tract infection in children," Recent Patents on Inflammation \& Allergy Drug Discovery, vol. 13, no. 1, pp. 2-18, 2019.

[30] B. Dai, Y. Liu, J. Jia, and C. Mei, "Long-term antibiotics for the prevention of recurrent urinary tract infection in children: a systematic review and meta-analysis," Archives of Disease in Childhood, vol. 95, no. 7, pp. 499-508, 2010.

[31] K. N. Saperston, D. J. Shapiro, A. L. Hersh, and H. L. Copp, “A comparison of inpatient versus outpatient resistance patterns of pediatric urinary tsract infection," Journal of Urology, vol. 191, no. 5S, pp. 1608-1613, 2014.

[32] I. Ali, M. Shabbir, and N. U1 Iman, "Antibiotics susceptibility patterns of uropathogenic $E$. coli with special reference to fluoroquinolones in different age and gender groups," Journal of the Pakistan Medical Association, vol. 67, no. 8, pp. 1161$1165,2017$.
[33] P. O. Okunola, M. O. Ibadin, G. E. Ofovwe, and G. Ukoh, "Coexistance of urinary tract infection and malaria among children under 4 years old: a report from Benin City, Nigeria," Saudi Journal of Kidney Diseases and Transplantation, vol. 29, pp. 231-234, 2012.

[34] O. Megged, "Staphylococcus aureus urinary tract infections in children are associated with urinary tract abnormalities and vesico-ureteral reflux," Pediatric Nephrology, vol. 29, no. 2, pp. 269-272, 2014.

[35] I. C. A. R. Barros, A. U. Ribeiro, and A. C. V. Costa, "Microorganisms prevalent in urinary tract infections and antimicrobial sensitivity profile: analysis of patients attending at the military police Hospital of the State of Goiäs, Brazil, in the period from 1998 to 2008," Journal of Health Science Institutions, vol. 29, no. 4, pp. 243-247, 2011.

[36] S. Ruppel, C. Hecht-Buchholz, R. Remus, U. Ortmann, and R. Schmelzer, "Settlement of the diazotrophic, phytoeffective bacterial strain Pantoea agglomerans on and within winter wheat: an investigation using ELISA and transmission electron microscopy," Plant and Soil, vol. 145, no. 2, pp. 261-273, 1992.

[37] A. T. Cruz, A. C. Cazacu, and C. H. Allen, "Pantoea agglomerans, a Plant pathogen causing human disease," Journal of Clinical Microbiology, vol. 45, no. 6, pp. 1989-1992, 2007.

[38] S. A. Brian and H. C. Sarah, "Urinary tract infection in children," American Family Physician, vol. 72, no. 12, pp. 25832588, 2005.

[39] T. Hameed, A. al Nafeesah, S. Chishti, M. al Shaalan, and K. al Fakeeh, "Community-acquired urinary tract infections in children: resistance patterns of uropathogens in a tertiary care center in Saudi Arabia," International Journal of Pediatrics and Adolescent Medicine, vol. 6, no. 2, pp. 51-54, 2019.

[40] P. Baral, S. Neupane, B. P. Marasini, K. R. Ghimire, B. Lekhak, and B. Shrestha, "High prevalence of multidrug resistance in bacterial uropathogens from Kathmandu, Nepal," BMC Research Notes, vol. 5, no. 1, p. 38, 2012.

[41] American Academy of Pediatrics, "Circumcision policy statement. American Academy of Pediatrics Task Force on Circumcision," Pediatrics, vol. 103, no. 3, pp. 686-693, 1999.

[42] K. Frumkin, "Bacteriology of urinary tract infections in emergency patients aged $0-36$ months," Journal of Emergency Medicine, vol. 48, no. 4, pp. 405-415, 2015.

[43] C. Marquez, M. Labbate, C. Raymondo et al., "Urinary tract infections in a South American population: dynamic spread of class 1 Integrons and multidrug resistance by homologous and site-specific recombination," Journal of Clinical Microbiology, vol. 46, no. 10, pp. 3417-3425, 2008. 